\title{
AS TÉCNICAS DE NEUROMARKETING NOS CONTRATOS ELETRÔNICOS E O VÍCIO DO CONSENTIMENTO NA ERA DIGITAL
}

\author{
NEUROMARKETING METHODS IN E-CONTRACTS AND THE VICE OF CONSENT IN THE \\ DIGITAL AGE
}

LAS TÉCNICAS DE NEUROMARKETING EN LOS CONTRATOS ELECTRÓNICOS Y EL VICIO DEL CONSENTIMIENTO EN LA ERA DIGITAL

\section{Charles Emmanuel Parchen ${ }^{1}$}

\section{Cinthia Obladen de Almendra Freitas ${ }^{2}$}

\section{Jussara Maria Leal de Meireles ${ }^{3}$}

Licença CC BY:

Artigo distribuído sob os termos Creative Commons, permite uso e distribuição irrestrita em qualquer meio desde que o autor credite a fonte original.

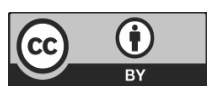

\begin{abstract}
Resumo: A sociedade contemporânea vive alterações sociais e comportamentais à medida que novas tecnologias são desenvolvidas e incorporadas ao dia a dia. Vive-se a quebra de paradigmas. Conceitos como velocidade, mobilidade e distância estão em modificação e o consumidor necessita usar produtos e serviços que em suas cláusulas contratuais preveem a Mineração de Dados como mecanismo de coleta, filtragem e catalogação dos gostos e das preferências. Os dados pessoais fomentam um mercado lucrativo, que lança mão de técnicas de neuromarketing para existir e se retroalimentar. Propõe-se a mudança de paradigma do atual mercado de compartilhamento de dados, por meio da atuação do Poder Judiciário, que, por exemplo, pode ser instado a revisar ou a modificar as cláusulas contratuais consideradas desproporcionais ao consumidor. Por meio do método dedutivo, o artigo analisa os vícios do consentimento em contratos eletrônicos sob a ótica do neuromarketing como técnica que fomenta o consumo irrefletido e compulsivo.
\end{abstract}

1 Doutorando em Direito Econômico e Socioambiental pela Pontifícia Universidade Católica do Paraná (PUC/ PR). Mestre em Direito Econômico e Socioambiental pela PUCPR. Especialista em Direito Processual Civil pela PUCPR e em Direito Privado pela Universidade Gama Filho-RJ. Advogado. Professor do curso de Direito do Centro Universitário Curitiba (UNICURITIBA), Curitiba-PR, Brasil. Professor do curso de Direito das Faculdades Santa Cruz - Curitiba-PR, Brasil. E-mail: charlesadv@gmail.com

2 Doutora em Informática pela PUCPR. Professora Titular da PUCPR da Escola de Direito-Curitiba-Paraná-Brasil. Professora Permanente do Programa de Pós-Graduação Econômico e Socioambiental (Mestrado e Doutorado) da PUCPR- Curitiba-PR, Brasil. E-mail: cinthia@ppgia.pucpr.br

3 Graduada em Direito pela Universidade Federal do Paraná, com Mestrado em Direito das Relações Sociais pela Universidade Federal do Paraná, Doutorado em Direito das Relações Sociais pela Universidade Federal do Paraná e Pós-Doutorado no Centro de Direito Biomédico da Universidade de Coimbra. Procuradora Federal na UFPR. Professora Titular de Direito Civil da Pontifícia Universidade Católica do Paraná, Professora do Quadro Permanente do Programa de Pós-Graduação em Direito Econômico e Socioambiental (Mestrado e Doutorado) da PUCPR - Curitiba-PR, Brasil. E-mail: jumeirelles29@gmail.com 
Palavras-chave: novas tecnologias; neuromarketing; vício do consentimento; contrato; consumidor.

\begin{abstract}
Contemporary society is undergoing social and behavioral changes, as new technologies are developed and incorporated into everyday life. Paradigms are being broken. Concepts such as speed, mobility and distance are being modified, and the consumer requires products and services that cover, in their contractual clauses, Data Mining as a mechanism for collecting, filtering and cataloging their tastes and preferences. Personal data is a profitable market, that uses neuromarketing techniques to exist and provide itself with feedback. This paper propose a paradigm shift from the current data sharing market, through the Judiciary, which may, for example, be required to revise or modify contractual clauses considered disproportionate to the consumer. Based on the deductive method, the paper analyzes the vices of consent in electronic contracts from the point of view of neuromarketing as a technique that encourages reckless and compulsive consumption.
\end{abstract}

Keywords: new technologies; neuromarketing; vice of consent; contract; consumer.

Resumen: La sociedad contemporánea vive cambios sociales y comportamentales en medida que nuevas tecnologías son desarrolladas e incorporadas al día a día. Se vive la quiebra de paradigmas. Conceptos como velocidad, movilidad y distancia están en modificación y el consumidor necesita usar productos y servicios que en sus cláusulas contractuales predicen la Minería de Datos como mecanismo de recolección, filtración y catalogación de los gustos y las preferencias. Los datos personales fomentan un mercado lucrativo, que abre mano de técnicas de neuromarketing para existir y se retroalimentar. Se propone el cambio de paradigma del actual mercado de compartimiento de datos, por medio de la actuación del Poder Judiciario, que, por ejemplo, puede ser instado al revisar o, a modificar las cláusulas contractuales consideradas desproporcionales al consumidor. Por medio del método deductivo, el artículo analiza los vicios del consentimiento en contratos electrónicos desde la óptica del neuromarketing como técnica que fomenta el consumo irreflexivo y compulsivo.

Palabras clave: nuevas tecnologías; neuromarketing; vicio del consentimiento; contrato; consumidor.

\title{
INTRODUÇÃO
}

Atualmente nenhuma publicidade ou oferta de produtos e serviços está dissociada da aplicação de técnicas de neuromarketing. Com efeito, como técnica derivada do estudo do comportamento e, principalmente, do cérebro humano e suas interações, possibilita fomentar o consumo impulsivo e, assim, aumentar a lucratividade das empresas.

Neste contexto, o neuromarketing, incidindo nos elementos límbicos e reptilianos do cérebro humano, faz com que o ato de consumir seja impensado ou não raciocinado. O neuromarketing reveste-se de importância, visto que é "Um 
processo de intercâmbio que cada um dos atores do sistema universal realiza para satisfazer desejos e necessidades" ${ }^{4}$. O consumidor preenche 3 (três) condições básicas: capacidade de compra, capacidade de pagamento e poder de decisão. $\mathrm{E}$ é na terceira condição básica que os contratos eletrônicos "operaram" mudanças via técnicas de neuromarketing, pois tal técnica está relacionada com a análise das sensações que o consumidor experimenta no processo de compra de um produto ou serviço. E esta técnica, quando submetida ao contexto da sociedade tecnológica contemporânea, encontra principalmente nos contratos digitais um nicho de mercado poderoso, ou seja, o do compartilhamento remunerado de dados pessoais dos consumidores.

A aplicação de métodos de Mineração de Dados é meio insidioso pelo qual os dados pessoais são extraídos do aparato tecnológico e está expressamente previsto nas cláusulas contratuais dos produtos e dos serviços baseados na Internet. Somam-se a estes métodos as técnicas de neuromarketing, que podem persuadir o consumidor a produzir mais dados e informações, causando a dependência destes produtos e serviços que só subsistem graças à produção diária e incessante de dados que precisam ser filtrados, categorizados e catalogados para serem transformados em conhecimento passível de ser repassado, podendo até mesmo ser comercializado direta ou indiretamente aos anunciantes dispostos a obter as preferências e os gostos dos usuários e dos consumidores que servirão de base ao direcionamento de publicidade segmentada e personalizada.

O foco do presente artigo é a reflexão acerca do neuromarketing como ferramenta usada pelos fornecedores de produtos e serviços baseados na Internet para, incidindo no consentimento do consumidor, fomentar o consumo impulsivo. A análise passa pelos requisitos da formação do contrato, bem como pelas cláusulas contratuais que, por meio da Mineração de Dados, compelem o consumidor a fornecer seus dados pessoais e não pessoais, expondo-o a riscos, como a perda da sua privacidade e intimidade e exacerbando a sua vulnerabilidade.

Dentro da perspectiva do princípio constitucional da proteção integral ao consumidor, preconizado no artigo $5^{\circ}$, inciso XXXII e 170, inciso $\mathrm{V}$, bem como das 4 CAYUELA, Oscar Malfitano; REQUENA, Ramiro Arteaga; ROMANO, Sofia Edith; SCINICA, Elsa Beatriz. Neuromarketing: para recobrar a confiança com os clientes. Trad. Maya Reyes. Rio de Janeiro: Qualitymark Editora, 2011. p.12. 
normas presentes nos artigos 138 a 165 do Código Civil, e da proteção especial da Lei 8.078/90, reflete o presente artigo sobre o elemento volitivo jurídico necessário à formação do contrato sobre os vícios do consentimento que o neuromarketing gera, estando apto, portanto, a causar a anulação do contrato ou das cláusulas que espoliam dados pessoais ou não pessoais e demais informações, bem como propõe que os mencionados estatutos jurídicos protetivos sejam utilizados para mitigar ou coibir os nefastos efeitos socioambientais do neuromarketing e da Mineração de Dados sobre a sociedade tecnológica.

\section{CONCEITOS BÁSICOS DE NEUROCIÊNCIA, MARKETING E NEUROMARKETING}

Para poder melhor compreender o neuromarketing como técnica visando ao incentivo ao consumo, necessário se faz abordar, ainda que de forma breve, a sua origem na chamada neurociência. Esta se constitui em disciplina gênero, cujas neuroeconomia, neurociência social, neuroanatomia, neurobiologia eneuropsicologia são algumas espécies, tendo objetivo "buscar explicar como a cognição e a consciência humana nascem da atividade do cérebro" ${ }^{\prime \prime}$, podendo ser conceituada como "o conjunto das disciplinas que estudam, pelos mais variados métodos, o sistema nervoso e a relação entre as funções cerebrais e mentais" ${ }^{\prime \prime}$. A neurociência é oriunda da curiosidade humana proveniente desde as dissecações em cadáveres humanos praticadas no antigo Egito, mas que se fortaleceu como teoria científica a partir da publicação de estudos sobre os ventrículos cerebrais de Galeno (130-200 d.C.), Descartes (1596-1650 d.C.) e Leonardo da Vinci (1472-1519 d.C.).

Com René Descartes (1596-1650), fixa-se o dualismo entre a mente e o corpo, cuja "consciência tornou-se o lugar da razão"7. O "penso, logo existo", portanto, torna-se a expressão máxima do racionalismo cartesiano a explicar como a razão deve preponderar sobre as emoções. A partir de 1800, com Franz Joseph Gall, desenvolveram-se vários métodos de estudo da mente, denominados de frenologia. A preocupação do cientista era com a localização das funções mentais no cérebro. Para tanto, usou de intricados processos como tomografia, cranioscopia e ressonância magnética em seus estudos ${ }^{8}$.

5 LENT, Roberto. Neurociência da mente e do comportamento. Rio de Janeiro: Guanabara Koogan S.A, 2008. p.2.

6 LENT, Roberto. Neurociência da mente e do comportamento. p.3

7 CAMARGO, Pedro Celso Julião de. Neuromarketing: a nova pesquisa de comportamento do consumidor. São Paulo: Atlas,2013. p.11.

CAMARGO, Pedro Celso Julião de. Neuromarketing: a nova pesquisa de comportamento do consumidor. p.26. 
Já em 1970, com Paul Maclean, desenvolve-se a teoria do cérebro tri-único, ou seja, dividido em três sistemas funcionais diferentes: reptiliano, límbico e córtex (ou neocórtex). O reptiliano seria o sistema responsável pelos instintos e, tal como nos répteis, serviria para atuar em caso de emergência e necessidade, em razão de uma fuga, por exemplo. Logo, está ligado à sobrevivência ou à tomada de decisões impulsivas e não raciocinadas ${ }^{9}$. Já o límbico é responsável pelas emoções ${ }^{10}$ :

Contudo, nem todas as ações mentalmente causadas resultam de um tal processo de pensamento. Considere o caso de um motorista que para o carro diante do semáforo vermelho, ou de uma pessoa que cumprimenta outra, que tranca a porta da casa ao sair, que acende a luz ao entrar. Na maioria das vezes em que fazemos essas coisas não precisamos realizar nenhum raciocínio, nenhum cálculo deliberativo. Contudo, nem por isso essas ações se tornam autônomas, pois diversamente das últimas elas resultam de uma vontade e intenção conscientes. Elas não são nem raciocinadas nem autônomas, mas algo intermediário, que quero chamar de ação volicional ${ }^{11}$.

E o córtex (ou neocórtex), uma vez responsável pela racionalidade e "pela consciência introspectiva"12, difere os seres humanos das demais espécies desprovidas de tal sistema. Assim, a proposição deste artigo é salientar que, para que qualquer decisão consciente possa ocorrer, é necessário um esforço deliberado e, portanto, voluntário. Logo, trata o córtex do processo de escolha e determinação sobre algum objeto ou coisa.

A neurociência, portanto, estuda cada função e área do cérebro, analisando o elo entre as reações cerebrais e o comportamento humano, bem como as questões sociais e biológicas que se apresentam de tal interação. Para tanto, lança mão de ferramentas como a biologia, a genética, a fisiologia e a anatomia, bem como da psicologia ${ }^{13}$.

A respeito desta última citada ciência, importa destacar o behaviorismo como vertente dedicada ao estudo do comportamento humano e à demonstração

9 LUIZ, Claiton. A teoria do cérebro triúnico e o neuromarketing. 2013. Disponível em: <http://linecoaching.com. br/site/a-teoria-do-cerebro-triunico-e-o-neuromarketing-parte-i-cerebro-reptiliano/>. Acesso em: 11 ago. 2016.

10 SCHENKMAN, Margaret L; BOWMAN, James P; GISBERT, Robyn L; BUTLER, Russel B. Neurociência clínica e reabilitação. Barueri: Manole, 2016. p.585.

11 COSTA, Cláudio F. Três níveis de ação. Ethica Revista Internacional de Filosofia da Moral da UFSC. Florianópolis, v.4, nº 1, p. 86, jun. 2005.

12 COSTA, Cláudio F. Três níveis de ação. Ethica Revista Internacional de Filosofia da Moral da UFSC. p.91.

13 PURVES, Dale; AUGUSTINE, George J; FITZPATRICK, David; HALL, William C; LAMANTIA, Anthony-Samuel. Neurociências. $4^{\mathrm{a}}$ ed. São Paulo: Artmed Editora, 2010. p.1. 
do condicionamento do cérebro humano e este como parte da terapia comportamental ${ }^{14}$. Tem o behaviorismo como premissa fundamental:

A ideia de que o ser humano tende a fazer coisas pela qual é recompensado e não pelas quais é punido, o que denota a forte influência externa no comportamento. Assim, não há vontade intrínseca, pois é sempre o estímulo externo que determina o comportamento ${ }^{15}$.

Também a psicanálise e o estudo do inconsciente na formação do agir humano, bem como a análise dos processos automáticos cerebrais, dão novo rumo à neurociência, que passa a se preocupar cada vez mais com o estudo das áreas do cérebro responsáveis por tal automatismo e suas consequências.

Feitas estas breves explanações acerca da neurociência, deve-se passar pela análise do marketing como técnica de negócio caracterizada como sendo "a atividade, conjunto de instituições e processos para criar, comunicar, entregar e trocar ofertas que têm valor para os clientes, parceiros e sociedade em geral"16 ou ainda "entender e atender as necessidades do consumidor"17. E neste contexto, "é mais do que natural que a informação assuma grande relevância, tanto como um bem jurídico ou econômico"18.

Tendo como premissa fundamental "descobrir a necessidade e os desejos dos clientes em potencial e satisfazê-los"19, esta só pode ser plenamente atendida se o comportamento do consumidor for esmiuçado e estudado. Logo, o marketing não está alheio a todas as descobertas científicas que desvendam o cérebro humano e o comportamento.

Em sua obra 'Brainfluence: 100 ways to persuade and convince consumers with neuromarketing', Roger Dooley chama a atenção para o percentual de inconsciência que determina o ser humano: "95 por cento de nossos pensamentos, emoções e aprendizado ocorrem sem nossa consciência, de acordo com o professor de

14 As experiências de condicionamento em cães tornaram Ivan Pavlov o maior expoente do behaviorismo.

15 CAMARGO, Pedro Celso Julião de. Neuromarketing: a nova pesquisa de comportamento do consumidor. p.5.

16 AMERICAN MARKETING ASSOCIATION. Definition of marketing. 2013. Disponível em: <https://www.ama.org/ AboutAMA/Pages/Definition-of-Marketing.aspx>. Acesso em: 11 ago. 2016.

17 FERREIRA Junior, Achiles Batista. Marketing digital: uma análise do Mercado 3.0. Curitiba: Intersaberes, 2015. p.43.

18 BRASIL. Escola Nacional de Defesa do Consumidor. A proteção de dados pessoais nas relações de consumo: para além da informação creditícia. Escola Nacional de Defesa do Consumidor; elaboração Danilo Doneda. - Brasília: SDE/DPDC, 2010. p. 17. Disponível em: <http://www.justica.gov.br/seus-direitos/consumidor/Anexos/manual-de-protecao-de-dados-pessoais. pdf>. Acesso em: 11 ago. 2016.

19 KERIN, Roger A.; HARTLEY, Steven W.; BERKOWITZ, Eric N.; RUDELIUS, W. Marketing. 8. ed. Porto Alegre: AMHG Editora Ltda, 2007. p. 8. 
marketing em Harvard e autor Gerald Zaltman"20. A frase: "Um diamante é para sempre" é muito conhecida. E como Dooley comenta é um bom exemplo de anúncio que, escrupulosamente, evita dar sugestões de valor em dinheiro. Com certeza, o consumidor já se deparou com preços que seguem o padrão: $R \$ 9,99$ ou $\mathrm{R} \$ 9$,90. Ou, ainda, Dooley apresenta que "... o cérebro das pessoas experimenta mais prazer quando elas pensam que estão bebendo um vinho de $\$ 45$ e não de $\$ 5$ a garrafa, mesmo quando na realidade, os dois são de baixa qualidade!"21. Emoção, consumo e influência para sugerir, recomendar e auxiliar na tomada de decisão.

Tais constatações esclarecem que, tendo por escopo o entendimento do comportamento humano, os profissionais do mercado passaram a recorrer à neurociência, já que esta foi capaz de, como método científico, dar a certeza de que o processo decisório e comportamental do ser humano se faz, em sua maioria, de forma automática e dentro de uma inconsciência oriunda da mente e do cérebro humano em seu sistema reptiliano e límbico.

O desvendar do automatismo e do inconsciente cerebral proporcionado pela neurociência mudou a forma como o marketing passou a enxergar a relação do mercado com o cliente. E sem ser a pretensão do presente texto aprofundar a questão dos estudos que foram feitos sobre a anatomia, o sistema nervoso e a constituição do cérebro humano ${ }^{22}$, insta salientar que evolução das ciências biológicas e sociais e também da curiosidade humana pelo comportamento, aliado ao capitalismo liberal, a sociedade de massa, a necessidade de criação de novas demandas consumidoras ou nichos mercadológicos, bem como o advento das novas tecnologias, deram azo ao surgimento do neuromarketing, técnica de fomento ao consumo que é a base para o presente artigo.

Mapeando o cérebro humano usando de artifícios da medicina, tais como: eletroencefalograma, ressonância magnética e outros exames; o objetivo é identificar as áreas do cérebro humano e analisar as atividades cerebrais que ocorrem quando submetidas a estímulos como publicidade, propaganda política, produtos expostos em vitrines, dentre outros. Assim, é possível verificar como o 20 "Ninety-five percent of our thoughts, emotions, and learning occur without our conscious awareness, according to Harvard marketing professor and author Gerald Zaltman”. DOOLEY, Roger. Brainfluence: 100 ways to persuade and convince consumers with neuromarketing. Hoboken, US: Wiley, 2011. ProQuest ebrary. Web. 24 August 2016. p.1.

21 DOOLEY, Roger. Brainfluence: 100 ways to persuade and convince consumers with neuromarketing. Hoboken, US: Wiley, 2011. ProQuest ebrary. Web. 24 August 2016. p.17.

22 Neste sentido, vide LENT, Roberto. Neurociência da mente e do comportamento. p.3 
consumidor reage, bem como a análise do seu inconsciente, aferindo o que ele gosta ou não, bem como o que deseja e sente.

\section{A SOCIEDADE TECNOLÓGICA COMO CENÁRIO AO NEUROMARKETING E À MINERAÇÃO DE DADOS}

Sabendo que as decisões impulsivas, emocionais e não racionais são as maiores responsáveis pelo consumo ${ }^{23}$, o neuromarketing explora a fundo os sistemas reptiliano e límbico do cérebro humano em busca da indução ou da sugestão do automatismo e do inconsciente, usando artifícios que ativem ou os exacerbem, bem como que produzam emoções e sensações de prazer no cérebro, diminuindo, portanto, a atuação ou a preponderância do córtex responsável pela decisão racional.

Verifica-se que o neuromarketing é ferramenta que pode potencializar o consumo, pois se vale de uma visão multidisciplinar para, estudando o mecanismo de ondas cerebrais bem como as sinapses e as regiões onde ocorrem estímulos, conseguir identificar se o ato humano está ocorrendo por impulso (cérebro reptiliano), por elementos como as emoções (sistema límbico) ou por puro raciocínio (córtex cerebral). Conhecedor destas informações, pode o fornecedor aplicar tais técnicas para moldar ou conduzir o comportamento do consumidor, visando ao aumento das vendas e da lucratividade.

Ocorre que, quando o assunto é a sociedade contemporânea, o uso do neuromarketing éinsidioso eaumenta a vulnerabilidade do consumidor.Isso porque a velocidade de acesso à informação causada pelo advento da Internet banda larga se une à imediatidade e à instantaneidade da produção e da disseminação da informação que tem por base o uso em grande escala de smartphones, tablets, drones e computadores. O resultado é o consumo desenfreado e insustentável que se verifica, por exemplo, na chamada obsolescência programada24.

Expoentes do neuromarketing podem ser encontrados em produtos como o Youtube e o Facebook, por exemplo. Neles, há vasto emprego de uma gama infindável de cores, sons e movimentos proporcionados pelos videoclipes, fotos

23 DOOLEY, Roger. Brainfluence: 100 ways to persuade and convince consumers with neuromarketing. p.2.

24 TAMBARA, Isabelle; BATISTA, Osvaldo Henrique dos Santos; FREITAS, Cinthia Obladen de Almendra. A proteção do consumidor e as técnicas de neuromarketing no comércio eletrônico que potencializam sua vulnerabilidade.

Revista Direito Empresarial (Curitiba). Belo Horizonte, v. 11, 2014. p. 88/89. 
e uso desenfreado dos emojis ${ }^{25}$ como forma de dar a sensação de completa liberdade de expressão, causando, assim, sentimentos de conforto, acolhimento, bem-estar e prazer que não são encontrados nas mídias tradicionais, como o rádio e o jornal impresso.

Trata-se, portanto, de cases práticos e hodiernos de como os sistemas reptiliano e límbico dos seres humanos podem ser estimulados para proporcionar enormes sensações e emoções visando ao consumo.

Portanto, a aplicação do neuromarketing na sociedade contemporânea a deixa ainda mais exposta e hiperconectada, porque a imersão no mundo on-line é constantemente estimulada. Desta forma, e partindo-se do pressuposto de Zygmunt Bauman de que se vive atualmente uma sociedade líquida, verifica-se que há abundância de informação e esta não mais se consolida no tempo, pois as interações sociais se rearranjam de forma muito mais rápida que a assimilação e a maturação dos seus efeitos na sociedade:

'Líquido-moderna' é uma sociedade em que as condições sob as quais agem seus membros mudam num tempo mais curto do que aquele necessário para a consolidação, em hábitos e rotinas, das formas de agir. A liquidez da vida e a da sociedade se alimentam e se revigoram mutuamente. A vida líquida, assim como a sociedade líquido-moderna, não pode manter a forma ou permanecer por muito tempo ${ }^{26}$.

É na esteira desta falta de conformação sólida das relações humanas que a informação vai ser transformada pelo mercado capitalista liberal em mais um produto mercadológico passível de lucro: trata-se da informação como poder e dinheiro.

Desde a Segunda Guerra, a informação foi galgada a um patamar de crucial importância na conformação do poderio bélico e militar de nações hegemônicas. Como exemplo de tal afirmação, é necessário lembrar que a Internet, antes de se difundir a sociedade privada, era um produto criado com fins exclusivamente militares ${ }^{27}$.

E como a sociedade contemporânea é caracterizada por estar imersa no contexto da abundância de acesso à informação, é preciso lembrar que o 25 Emojis são aplicações que permitem o uso de desenhos para substituir o texto escrito e expressar sentimentos.

26 BAUMAN, Zygmunt. Vida líquida. 2. ed. Rio de Janeiro: Zahar: 2009, p.7.

27 Não é objeto do presente artigo abordar a questão do advento da Internet e suas características. Para maiores detalhes, vide: CASTELLS, Manuel. A sociedade em rede. A Era da Informação: economia, sociedade e cultura. v.1. São Paulo: Paz e Terra, 1999. 
mercado capitalista encontra, dentro de sua sistemática, mais uma maneira de se fortalecer, se renovar e incidir sobre todas as esferas da vida humana, pois consegue fazer da informação abstrata e genérica, uma espécie de 'mineral' precioso a ser explorado e posteriormente 'talhado e polido' para venda em um nicho de mercado altamente lucrativo.

Não é à toa que as cláusulas contratuais dos produtos e serviços baseados na Internet vão asseverar a coleta de dados como sendo a base da prática que se denomina Mineração de Dados ou Data Mining:

O termo mineração de dados (MD) foi cunhado como alusão ao processo de mineração descrito anteriormente, uma vez que se explora uma base de dados (mina) usando algoritmos (ferramenta) adequados para obter conhecimento (minerais preciosos). Os dados são símbolos ou signos não estruturados, sem significado, como valores em uma tabela, e a informação está contida nas descrições, agregando significado e utilidade aos dados, como o valor da temperatura do ar. Por fim, o conhecimento é algo que permite uma tomada de decisão para a agregação de valor, então, por exemplo, saber, que vai chover no fim de semana pode influenciar sua decisão de viajar ou não para a praia ${ }^{28}$.

A Mineração de Dados é uma prática consistente na extração forçada das informações para posterior revenda das mesmas a terceiros que irão oferecer publicidade direcionada e segmentada. O objetivo da Mineração de Dados é transformar o dado bruto (aquele sem significado ou estrutura) em dado 'limpo' ou categorizado e acessível de imediato a todos, oportunidade em que haverá, então, agregação de conhecimento.

Ocorre que este processo de agregação traz como pano de fundo este nefasto mercado de compartilhamento de dados pessoais e não pessoais a parceiros comerciais que estão dispostos a pagar por ele: trata-se da contraprestação que o consumidor é obrigado a dar em troca da possibilidade de usar um software 'gratuitamente'.

A base mercadológica da Mineração de Dados é, portanto, uma expropriação não consentida do conjunto de dados pessoais que, por sua vez, retroalimenta o

28 CASTRO, Leandro Nunes de; FERRARI, Daniel Gomes. Introdução à mineração de dados: conceitos básicos, algoritmos e aplicações. São Paulo: Saraiva, 2016. p.4. 


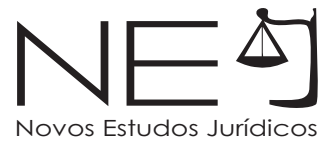

processo de mineração, haja vista a incessante necessidade de uma busca cada vez maior de novos dados a serem filtrados, para que depois possam ser vendidos.

A lógica capitalista, a qual está submetida aos dados pessoais do consumidor, demanda que, para que se possa oferecer publicidade dirigida e sedutora, os dados brutos ou genéricos que nada ou pouco revelem sobre as preferências de consumo $^{29}$ devam ser suprimidos, pois como visto, o processo de agregação de valor à informação é um trabalho altamente especializado que acaba por tornála muito valorizada e economicamente relevante. Eis o interesse dos produtos e dos serviços on-line em deixar de lado a privacidade de seus usuários, utilizandose de seus dados pessoais.

Os Termos de Uso e Políticas de Privacidade de produtos e serviços online são contumazes em praticar a Mineração de Dados para, expropriando a informação, repassá-la a parceiros comerciais dispostos a pagar altas cifras pelos gostos e pelas preferências pessoais dos consumidores. Tais cláusulas contratuais serão abordadas na sessão quatro.

Ocorre que, no Brasil, contra a prática destes maus atos, o consumidor conta com a proteção da legislação e dos princípios constitucionais da Dignidade da Pessoa Humana e da Integral Defesa do Consumidor. Além disto, há a normativa da Lei 8.078/90 (Código de Defesa do Consumidor - CDC), bem como aquelas relacionadas aos chamados vícios da vontade ou do consentimento, previstos no Código Civil. Tais normas são abordadas a seguir.

\section{A PROTEÇÃO DO CONSUMIDOR NA CONSTITUIÇÃO FEDERAL E NO CDC FRENTE À FORMAÇÃO DOS CONTRATOS E AOS VÍCIOS DO CONSENTIMENTO}

Perante a Constituição Federal da República do Brasil e também do Código de Defesa do Consumidor, é dever do fornecedor educar, informar e conscientizar para o consumo consciente, correto e sustentável.

O princípio da Dignidade da Pessoa Humana encontra-se no inciso III do art. $1^{\circ}$ e é o alicerce da proteção integral que a Constituição confere ao consumidor

29 FREITAS, Cinthia Obladen de Almendra. A vulnerabilidade do consumidor e a exposição pública na internet. In: Aires José Rover, Fernando Galindo. (Org.). III Encontro de Internacionalização do CONPEDI/Universidad Complutense de Madrid. 1. ed. Madrid: Ediciones Laborum, 2015, v. 9, p. 94. 
ao, no art. 50, inciso XXXII, destacar que o Estado deve promover a sua defesa. Ademais, o inciso V do art. 170 menciona, ao lado dos princípios da livre iniciativa, da justiça social e da ordem econômica, a defesa do consumidor ${ }^{30}$.

E se o monopólio do conhecimento técnico está nas mãos do fornecedor, e partindo do pressuposto de que todo ser humano é vulnerável aos riscos cotidianos, bem como hipossuficiente tecnicamente na relação consumerista, passa o consumidor a contar com a especial proteção da Lei 8.078/90 (Código de Defesa do Consumidor), que surgiu por expressa disposição constitucional, a fim de garantir a efetividade do princípio da Dignidade da Pessoa Humana também nas relações negociais consumeristas.

No contexto da informação na era digital, o desiderato de Justiça passa, necessariamente, pela conscientização do consumidor acerca dos seus direitos de privacidade e intimidade, a teor do que dispõe o art. 106, inciso IV do CDC:

Art. 106. O Departamento Nacional de Defesa do Consumidor, da Secretaria Nacional de Direito Econômico (MJ), ou órgão federal que venha substituí-lo, é organismo de coordenação da política do Sistema Nacional de Defesa do Consumidor, cabendo-lhe: IV - informar, conscientizar e motivar o consumidor através dos diferentes meios de comunicação ${ }^{31}$.

Esta necessidade de conscientização por meio do Estado é de extrema importância nos dias atuais, pois uma vez inserido no contexto tecnológico, o consumidor deixa de ser vulnerável e passa a ser hipervulnerável diante da potencialização, no ambiente digital, dos riscos e dos efeitos a que ele está sujeito.

Em razão da vulnerabilidade, o Código de Defesa do Consumidor vai, então, enquadrar como abusiva a publicidade que não informa sobre dado essência do produto ou serviço (art. 37, parágrafo $3^{\circ}$ ), bem como vai obrigar o fornecedor a veicular as informações de forma facilmente identificável (art. 36).

Ademais, em caso de qualquer infração aos princípios constitucionais bem como aos deveres que o Código de Defesa do Consumidor imputa ao fornecedor,

30 BRASIL. Constituição da República Federativa do Brasil. Brasília, DF: Senado Federal, 1988. Disponível em: <http://www.planalto.gov.br/ccivil_03/constituicao/constituicao.htm>. Acesso em: 11 ago. 2016.

31 BRASIL. Lei $\mathbf{n}^{\circ} \mathbf{8 . 0 7 8}$, de 11 de setembro de 1990. Código de Defesa do Consumidor. 1990. Disponível em: <http://www.planalto.gov.br/ccivil_03/leis/L8078.htm>. Acesso em: 11 ago. 2016. 
é direito do consumidor a modificação e a revisão das cláusulas que lhe imputem obrigações excessivas, iníquas ou abusivas (conforme se infere do inciso $\mathrm{V}$ do art. $6^{\circ}$ do $(D C)$, até porque elementos como a boa-fé objetiva, que imputa às partes contratantes a observância de verdadeiros deveres positivados no Código Civil (entre eles a lealdade, a probidade, a segurança, o solidarismo, a fraternidade e o cuidado), permeiam todas as relações negociais que se submetem à legislação brasileira.

A razão de ser desta lógica é a de que, nos contratos regidos pelo Código Civil, a contratação deva ser a mais paritária possível para as partes, que são tratadas nas mesmas condições e possuem o mesmo poder de negociação. Por sua vez, nos contratos submetidos à incidência do CDC, não obstante muitos deles serem conformados pela via massificada da adesão (tais como os que ocorrem na maioria dos casos de produtos e serviços baseados na Internet), ainda por cima o consumidor sempre será a parte mais fraca da relação negocial, pois, uma vez que hipossuficiente e vulnerável, deve ser especialmente protegido contra as más práticas do mercado.

Não obstante, é requisito para a formação de todo e qualquer contrato no Brasil o acordo de vontades. E para haver este, deve ocorrer um processo raciocinado de negociações prévias, apresentação da proposta e da aceitação que irá compor o contrato definitivo. Para Maria Helena Diniz, há três momentos psíquicos que irão formar a vontade jurídica que embasa o contrato: o momento da solicitação, o da deliberação e o da ação ${ }^{32}$. O momento da solicitação é aquele em que há "atuação exógena sobre o psiquismo"; o da deliberação é o da "elaboração interior" e o da ação é a "exteriorização do trabalho mental"33.

Verifica-se que o ponto de partida para a formação do contrato é um estímulo interno que fará com que a pessoa o internalize e reaja, ponderando o que quer. Este querer interno que, por sua vez, será a base para sua posterior exteriorização. É este ato de "publicidade" do querer interno que o Direito se ocupa e entende como sendo o elemento volitivo jurídico da vontade base para a formação do contrato ${ }^{34}$. A vontade, para o contrato, portanto, é formada por dois elementos: um interno, de elaboração; e outro externo, a publicidade do querer.

32 DINIZ, Maria Helena. Curso de direito civil brasileiro. Teoria das obrigações contratuais e extracontratuais. Vol. 3. 30. ed. São Paulo: Saraiva, 2014.p. 56.

33 DINIZ, Maria Helena. Curso de direito civil brasileiro. Teoria das obrigações contratuais e extracontratuais. p. 56.

34 DINIZ, Maria Helena. Curso de direito civil brasileiro. Teoria das obrigações contratuais e extracontratuais. p. 56/57. 
É proposição do presente artigo dizer que é a junção destes dois elementos o que compõe o processo de raciocínio necessário à formação do contrato, bem como o consentimento necessário ao mesmo.

Portanto, a atuação do córtex cerebral, responsável pela racionalidade, é fundamental para que se possa falar em elemento volitivo jurídico: a ação que compõe a formação do contrato e que deve alcançar o ato jurídico perfeito, ou seja, sua consecução até seu exaurimento com a geração de benefícios não só às partes contraentes, mas também a toda sociedade, na medida em que o princípio da função social do contrato vige muito fortemente no ordenamento jurídico brasileiro.

O ordenamento jurídico brasileiro privilegia e reconhece a crucial importância do livre pensar e agir para que possa haver contratação. Não é à toa que, prevendo a possibilidade de que o consentimento possa sofrer algum tipo de interferência que prejudique a volição jurídica da vontade, trouxe expressamente disposto nos artigos 138 a 184 do Código Civil, diversas figuras de invalidade do negócio jurídico, entre elas, os chamados vícios do consentimento.

Conforme Capítulo IV do Livro III do Código Civil35, eles são considerados defeitos nos negócios jurídicos que podem, dentro da perspectiva do princípio da conservação dos contratos, serem sanados com a ratificação do negócio pelas partes contraentes, caso desejem.

Portanto, os vícios do consentimento causam a anulação do contrato ou de suas cláusulas que padeçam de tais vícios. Dentre eles, pode-se citar o erro, a coação, a fraude e a lesão. A consequência jurídica da anulação é a restituição das partes ao estado em que se encontravam antes da avença e, se não for possível, a indenização equivalente ${ }^{36}$.

A existência dos mencionados defeitos do negócio jurídico se justifica porque é em torno do elemento 'aceitação' (que compõe o acordo de vontades necessário à existência de todo e qualquer contrato) que gira toda a controvérsia

35 BRASIL. Lei n. 10.406, de 10 de janeiro de 2002. Institui o Código Civil. 2002. Disponível em: <http://www. planalto.gov.br/ccivil_03/leis/2002/L10406.htm>. Acesso em: 11 ago. 2016.

36 MARTINS, Fran; CORREAA, Osmar Brina. Contratos e obrigações comerciais. 16. ed. Rio de Janeiro: Forense, 2010. p.95. 
acerca da força obrigatória dos mesmos. E para que haja aceitação, deve ocorrer clara internalização, ponderação e manifestação raciocinada da vontade por meio do agir, de modo que, no próximo capítulo, são apresentadas as consequências da ausência ou da mitigação do elemento volitivo jurídico, ou vontade externada, causadas pelo neuromarketing e seus reflexos na formação do contrato e na validade de suas cláusulas.

\section{O NEUROMARKETING COMO VÍCIO DO CONSENTIMENTO APTO A ANULAR AS CLÁUSULAS CONTRATUAIS QUE EXPROPRIAM A INFORMAÇÃO}

Como visto, o neuromarketing não se preocupa com processos racionais e conscientes. É proposição do presente artigo asseverar que tal técnica se vale dos ensinamentos de condicionamento e mecanismos de recompensa analisados pelo behaviorismo para, incidindo nos sistemas límbico e reptiliano, explorar suas características e potencializar o automatismo e a inconsciência, visando apenas ao consumo desmedido. Neste sentido, afirma o doutor em farmacologia, Fabrício Pamplona:

A vasta compreensão neurocientífica do sistema de recompensa, com a participação fundamental de circuitos neurais dopaminérgicos pode ser aplicada em algo aparentemente distante como marketing, gerando o híbrido neuromarketing. Em uma forma mais ampla, podemos falar mesmo em neuroeconomia, uma área de vanguarda, na intersecção entre ambos os campos do conhecimento humano ${ }^{37}$.

E prossegue:

Antigamente o sistema de recompensa era muito associado à dependência de drogas, e continua sendo, mas, numa estratégia inovadora, percebemos que há muita semelhança entre o que nos faz consumir algo que nos dá prazer imediato, químico, e a motivação que nos faz comprar um produto. Até aí tudo bem, é a curiosidade do ser humano e a avidez por novidades a todo vapor. Contudo, existe um ponto em que o consumo deixa de ser algo prazeroso e a compra se dá por outros motivos, relacionados à dor e à insatisfação pessoal ${ }^{38}$.

37 PAMPLONA, Fabrício; PERUZZO, Marcelo. Um milhão de motivos para se aprender neuromarketing. 2010. Disponível em: <http://www.marceloperuzzo.com.br/index.php/ conteudo/artigos/68-um-milhao-de-motivos-parase-aprender-neuromarketing>. Acesso em: 11 ago. 2016.

38 PAMPLONA, Fabrício; PERUZZO, Marcelo. Um milhão de motivos para se aprender neuromarketing. 2010. Disponível em: <http://www.marceloperuzzo.com.br/index.php/ conteudo/artigos/68-um-milhao-de-motivos-para- 
Desta forma, fazendo com que o inconsciente, os automatismos cerebrais e as emoções prevaleçam, o neuromarketing vai estimular o ser humano a agir por puro impulso e em claro detrimento do raciocínio. Como exemplo desta afirmação, salienta-se um célebre estudo nos Estados Unidos, que foi conduzido pelo Baylor College of Medicine no ano de 2001 e publicado na revista Neuron em 200439, e envolveu as marcas de refrigerante Coca-Cola e Pepsi. Foram usados 67 voluntários no estudo, que passaram por técnicas de monitoramento e escaneamento cerebral para análise das regiões estimuladas. O teste consistia basicamente na prova do conteúdo de três amostras líquidas, sendo uma com rótulo da Coca-Cola, outra da Pepsi e outra sem rótulo.

Embora a publicação do teste reconheça que, historicamente, a preferência por alimentos e bebidas se dá por questões culturais e em grande parte subjetivas, a mesma alerta para o fato de que modernamente:

Influências culturais sobre as nossas preferências comportamentais para alimentos e bebidas estão agora interligados com a conveniência biológica que moldou a versão inicial dos mecanismos de preferência subjacentes. Em muitos casos, influências culturais dominam o que comemos e bebemos. Evidências comportamentais sugerem que as mensagens culturais podem insinuar-se nos processos de tomada de decisão que produzem preferências por um consumível ou outro. Consequentemente, o apelo ou a repulsa de locais culturalmente relevantes, sons e memórias associadas contribuem para a construção moderna de preferências de comida e bebida. ${ }^{40}$.

Não há informações, na publicação sobre o teste, se os voluntários conheciam previamente o gosto dos líquidos ou, ainda, se nunca haviam ingerido refrigerantes de cola. Apenas consta que os testes foram realizados com versões descarbonatadas dos líquidos, ou seja, sem adição de água gaseificada.

se-aprender-neuromarketing>. Acesso em: 11 ago. 2016.

39 MCCLURE, Samuel M; LI, Jian; TOMLIN, Damon; CYPERT, Kim S; MONTAGUE, Latané M; MONTAGUE, P. Read. Neural correlates of behavioral preference for culturally familiar drinks. Neuron. Volume 44, issue 2, October 2004. p. 379387. Disponível em: <http://www.sciencedirect.com/science/article/pii/S0896627304006129>. Acesso em: 11 ago. 2016.

40 "Cultural influences on our behavioral preferences for food and drink are now intertwined with the biological expediency that shaped the early version of the underlying preference mechanisms. In many cases, cultural influences dominate what we eat and drink. Behavioral evidence suggests that cultural messages can insinuate themselves into the decision-making processes that yield preferences for one consumable or another. Consequently, the appeal or repulsion of culturally relevant sights, sounds, and their associated memories all contribute to the modern construction of food and drink preferences". MCCLURE, Samuel M; LI, Jian; TOMLIN, Damon; CYPERT, Kim S; MONTAGUE, Latané M; MONTAGUE, P. Read. Neural correlates of behavioral preference for culturally familiar drinks. p.387. 
Não obstante, todos os copos usados no teste trazerem em seu conteúdo apenas Coca-Cola, sendo que os voluntários não sabiam desta situação, o mesmo comportamento de escolha que foi observado com a Coca-Cola não ocorreu com os copos que possuíam o rótulo de Pepsi ${ }^{41}$.

Como a imensa maioria dos voluntários escolheu o conteúdo com o rótulo da Coca-Cola, o resultado deste estudo foi o de que a escolha pelo refrigerante é uma questão puramente cultural, psicológica e ligada à marca e predominantemente baseada no rótulo e no estímulo visual e sensorial que o mesmo causou nos voluntários.

Logo, pode-se inferir que a escolha não é racional e nem está ligada ao sabor ou às características do líquido, mas sim a elementos como o mecanismo de recompensa behaviorista, uma vez que o estudo concluiu que bebidas marrons, carbonadas e açucaradas servem de recompensa a muitos seres humanos e também a animais em testes laboratoriais ${ }^{42}$.

A escolha também está ligada ao marketing, visto que tanto a Pepsi quanto a Coca-Cola utilizam de mensagens que estimulam o sistema nervoso, bem como ao rótulo, já que a prevalência pela escolha da Coca-Cola foi atestada pelo número de pessoas que preferia esta marca em vez de visualizavam em alguns copos o rótulo vermelho do citado refrigerante.

Aproveitando-se da efemeridade das relações sociais digitais, o neuromarketing como técnica de mercado pode potencializar a dependência dos produtos e serviços conformados para a Internet, causando, por exemplo, sensações de onipotência, onipresença e onisciência de produtos e serviços como o Google, o WhatsApp, o Facebook, o Twitter e outros, ao mesmo tempo sem que o consumidor esteja ciente de que sua vida inteira é permeada pela informática e pela não possibilidade de desconexão à rede mundial de computadores. Com isto, ocorre na sociedade contemporânea a síndrome da dependência tecnológica:

A Síndrome da Dependência Tecnológica, também conhecida como tecnose, é uma doença psiquiátrica que decorre da utilização excessiva de recursos tecnológicos e da internet. Esta enfermidade tem bastante

41 MCCLURE, Samuel M; LI, Jian; TOMLIN, Damon; CYPERT, Kim S; MONTAGUE, Latané M; MONTAGUE, P. Read. Neural correlates of behavioral preference for culturally familiar drinks. p. 385.

42 MCCLURE, Samuel M; LI, Jian; TOMLIN, Damon; CYPERT, Kim S; MONTAGUE, Latané M; MONTAGUE, P. Read. Neural correlates of behavioral preference for culturally familiar drinks. p. 380. 
semelhança com as dependências químicas de drogas e álcool, inclusive seu tratamento é bem similar ${ }^{43}$.

Há, na sociedade contemporânea, a dependência de tecnologias que estimulam a produção incessante de dados e informações que podem ser mineradas, catalogadas e transformadas em conteúdo para ser repassado ou até mesmo vendido a terceiros dispostos a pagar para conhecer em detalhes os gostos e as preferências pessoais dos usuários e dos consumidores.

Portanto, diversos e nefastos efeitos socioambientais são verificados no contexto da prática do neuromarketing. A título de exemplo, menciona-se o fato de que esta técnica pode fomentar o uso de aplicativos e produtos que têm por base a Mineração de Dados que, por sua vez, pode causar a perda da privacidade, da intimidade e a hiperexposição do consumidor, isso sem falar no aumento do consumo, que pode ser tornar desenfreado. Neste sentido, assevera Fabricio Pamplona e Marcelo Peruzzo:

Quantas vezes percebemos que compramos produtos, que no ato da compra, sentimos um prazer, um alívio. Mas ao tê-los, acabamos nem usando. Porém, não nos sentimentos muitas vezes frustrados, justamente por ter resolvido o problema expectativa. Roupas e equipamentos para emagrecer são os campeões desta categoria. Decidimos comprar um produto muito antes de tê-lo visto, tocado e muitas vezes até de ter recursos para a compra. A expectativa organiza nosso cérebro de tal forma a criar uma necessidade imensa daquilo, com prioridade total, dominando nossos pensamentos. No entanto, quando finalmente conseguimos comprá-lo, sentimos que este produto já 'nos pertencia' de tanto que o namoramos na vitrine! 0 desafio e a expectativa passam a ser, comprar o próximo modelo. ${ }^{44}$

O neuromarketing oblitera a possibilidade do conhecimento, da conscientização e da ponderação da informação quando associado às técnicas de Mineração de Dados, muitas vezes, por puro dolo omissivo, porque os mecanismos de marketing são contumazes em não informar, em 'esquecer-se' de educar e conscientizar, tudo com o intuito de potencializar a lucratividade.

43 MENDONÇA, Gilson Martins; KOZICKI, Katya; COELHO, Sérgio Reis. O princípio da vulnerabilidade e as técnicas de neuromarketing: aprofundando o consumo como vontade irrefletida. Revista Scientia luris. Londrina, v. $18, \mathrm{n}^{\circ}$ 1.p.137, 2014.

44 PAMPLONA, Fabrício; PERUZZO, Marcelo. Um milhão de motivos para se aprender neuromarketing. 2010. Disponível em: <http://www.marceloperuzzo.com.br/index.php/ conteudo/artigos/68-um-milhao-de-motivos-parase-aprender-neuromarketing>. Acesso em: 11 ago. 2016. 
Como já foi visto, para que a informação possa ser vendida, ela precisa ser catalogada, filtrada e categorizada. E para que este processo de 'Mineração de Dados' ocorra, é necessário haver produção de informação relevante que irá se transformar em conhecimento disponível a todos, inclusive àqueles que queiram comprar. Frank Pasquale destaca a relevância da informação catalogada, filtrada e categorizada:

Quanto mais confiamos em motores de busca e redes sociais para encontrar o que queremos e precisamos, mais influência eles exercem. O poder de incluir, excluir e classificar é o poder de garantir que certas impressões públicas se tornem permanentes, enquanto outras continuem fugazes. ${ }^{45}$

Logo, como esta prática está sustentada na necessidade de existência incessante de dados, ela precisa ser retroalimentada diuturnamente. Portanto, precisa haver estímulo ao consumidor para que os dados sejam capturados pelos sistemas, aplicativos e serviços on-line e, também, que tal prática não fique adstrita ao particular, ou seja, esta técnica deve ser aplicada de modo compartilhado, de preferência, por meio da captura de postagens e conversações em chats e redes sociais.

Os mecanismos de check-in do Facebook, bem como o GPS de smartphones e a chamada Internet das Coisas ${ }^{46}$, são exemplos de aplicações tecnológicas que possibilitam até mesmo controlar a vida humana por meio da aferição incessante dos hábitos pessoais e, desta forma, visar a produção de enorme conteúdo informacional que pode ser minerado. Controle que, segundo Stefano Rodotà, ${ }^{47}$ acontece por diferentes motivos, ressaltando as constantes exigências de segurança nacional e internacional, os interesses de mercado e, ainda, a reorganização da administração pública. $E$, ainda, Danilo Doneda ${ }^{48}$ entende que a sociedade contemporânea inserida neste cenário tecnológico vai além do conceito individualista e do eixo pessoa-informação-segredo e, portanto, amplia-se à coletividade, refletindo sobre a relação pessoa-informação-circulação-controle.

45 "The more we rely on search engines and social networks to find what we want and need, the more influence they wield. The power to include, exclude, and rank is the power to ensure that certain public impressions become permanent, while others remain fleeting". PASQUALE, Frank. The black box society: the secret algorithms that control money and information. Cambridge: Harvard University Press, 2015. p. 14.

46 Não é intuito do presente artigo abordar a Internet das coisas. Neste sentido, vide: PRESSER, MIRKO. Inspirando a internet das coisas. Dinamarca: Alexandra Institute, 2011.

47 RODOTÀ, Stefano. A vida na sociedade da vigilância: a privacidade hoje. Tradução de Danilo Doneda e Luciana Cabral Doneda. Organização, seleção e apresentação de Maria Celina Bodin de Moraes. Rio de Janeiro: Renovar, 2008. 
Estabelece-se uma nova dinâmica em torno do usuário-consumidor pautada na informação e na comunicação, de modo a focar os relacionamentos intra e interpessoais, ou seja, a sociedade informacional.

E como este controle se dá, de preferência, da maneira 'invisível' aos olhos do usuário, o neuromarketing pode alavancar a criação de mecanismos de incentivo à 'não desconexão' ou, explicando de outro modo, pode auxiliar na dependência dos produtos e serviços, tais como WhatsApp, Facebook, Google e outros. Desta maneira, o consumidor não conseguirá saber ou discernir que, ao aderir aos Termos de Uso e Políticas de Privacidade do serviço ou produto baseado na Internet, está consentindo em permitir a prática da Mineração de Dados, que também irá se fazer acompanhar da autorização para o fornecedor minerar os dados e depois compartilhá-los.

A explicação a esta questão advém do fato de que até mesmo os Termos e Políticas estão envoltos em práticas de neuromarketing que suavizam a linguagem e a tornam menos direta e explicativa. Expressões como "compra e venda da informação" e "Mineração de Dados" são substituídas por "coleta", "ajuda" e "compartilhamento", que dão a impressão de que o consumidor faz parte de uma comunidade conectada que possui um objetivo altruístico maior de democratizar o acesso e tornar a informação algo grátis para possibilitar que o maior número de pessoas possível possa ter acesso irrestrito a ela. Neste sentido, vide cláusula da Política de Privacidade do Google ${ }^{49}$.

Podemos compartilhar informações que não sejam pessoalmente identificáveis publicamente e com nossos parceiros, como sites de editores, anunciantes ou sites relacionados. Por exemplo, podemos compartilhar informações publicamente para mostrar tendências sobre o uso geral dos nossos serviços ${ }^{50}$.

Também a cláusula do Facebook ${ }^{51}$ :

Trabalhamos com empresas terceirizadas que nos ajudam a fornecer e a melhorar nossos Serviços ou com empresas que usam anúncios e

49 GOOGLE. Política de privacidade. 2016. Disponível em: <https://www.google.com/intl/pt-BR/policies/privacy/>. Acesso em; 11 ago. 2016.

50 GOOGLE. Política de privacidade. 2016. Disponível em: <https://www.google.com/intl/pt-BR/policies/privacy/>. Acesso em: 11 ago. 2016.

51 FACEBOOK. Política de dados. 2015. Disponível em: <https://www.facebook.com/privacy/ explanation>. Acesso em: 11 ago. 2016. 
produtos relacionados, o que possibilita a operação de nossas empresas e o fornecimento de serviços gratuitos para pessoas do mundo inteiro ${ }^{52}$.

A explicação da oferta de melhora dos serviços pode ser encontrada em Danilo Doneda ${ }^{53}$ à medida que dois fatores são utilizados como justificativas para uso dos dados pessoais, a saber: o controle, já mencionado anteriormente, e a eficiência ora apresentada a partir das cláusulas das políticas de dados dos serviços on-line.

Se elementos como logomarcas, cores, sons, movimentos e até mesmo a semântica são usados para induzir o consumidor a aderir aos Termos e às Políticas que irão expropriar a sua informação pessoal e não pessoal, há claro vício de consentimento que autoriza, dentro da lógica protetiva da Constituição Federal de 1988, do dever de informar preconizado pelo CDC e pela teoria civilista dos vícios da vontade, o consumidor a pleitear, na prática, do Poder Judiciário, a revisão, a modificação ou a anulação das cláusulas contratuais que, expropriando a informação, aniquilam a privacidade e a intimidade.

No sentido da proteção normativa prevê o Código Civil ${ }^{54}$ no seu art. 138: "São anuláveis os negócios jurídicos, quando as declarações de vontade emanarem de erro substancial que poderia ser percebido por pessoa de diligência normal, em face das circunstâncias do negócio"55. Já o art. 139 assevera:

O erro é substancial quando: I - interessa à natureza do negócio, ao objeto principal da declaração, ou a alguma das qualidades a ele essenciais; II - concerne à identidade ou à qualidade essencial da pessoa a quem se refira a declaração de vontade, desde que tenha influído nesta de modo relevante; III - sendo de direito e não implicando recusa à aplicação da lei, for o motivo único ou principal do negócio jurídico ${ }^{56}$.

É possível identificar a proteção da vontade também por meio do art. 46 do Código de Defesa do Consumidor:

Os contratos que regulam as relações de consumo não obrigarão os consumidores se não thes for dada a oportunidade de tomar

52 FACEBOOK. Política de dados. 2015. Disponível em: <https://www.facebook.com/ privacy/explanation>. Acesso em: 11 ago. 2016.

53 DONEDA, Danilo. Da privacidade à proteção de dados pessoais. p.7.

54 BRASIL. Lei $\mathbf{n}$. 10.406, de 10 de janeiro de 2002. Institui o Código Civil. 2002. Disponível em: <http://www. planalto.gov.br/ccivil_03/leis/2002/L10406.htm>. Acesso em: 11 ago. 2016.

55 BRASIL. Lei n. 10.406, de 10 de janeiro de 2002. Institui o Código Civil. 2002. Disponível em: <http://www. planalto.gov.br/ccivil_03/leis/2002/L10406.htm>. Acesso em: 11 ago. 2016.

56 BRASIL. Lei n. 10.406, de 10 de janeiro de 2002. Institui o Código Civil. 2002. Disponível em: <http://www. planalto.gov.br/ccivil_03/leis/2002/L10406.htm>. Acesso em: 11 ago. 2016. 
conhecimento prévio de seu conteúdo, ou se os respectivos instrumentos forem redigidos de modo a dificultar a compreensão de seu sentido e alcance ${ }^{57}$.

Se o neuromarketing como técnica voltada ao incremento do consumo irracional, pois incide justamente nos elementos automáticos e inconscientes do cérebro humano, faz com que diminua a capacidade de raciocínio e exacerbe os sentimentos e as emoções em torno de uma tomada de decisão impulsiva, há que se concluir que o necessário ânimo ou vontade ponderada, deliberada e manifestamente exarada pelo consumidor está claramente prejudicada, mitigada ou muitas vezes até mesmo aniquilada por conta da imputação forçada de um mecanismo viciante no cérebro que sequer é perceptível.

É entendimento do presente artigo asseverar a clara incidência do instituto civil do erro quando o contrato, para existir, se vale da prática comercial do neuromarketing. A consequência jurídica de tal afirmação é a de que nenhum negócio jurídico que tenha por base qualquer prática de neuromarketing visando à Mineração de Dados poderá subsistir incólume.

É necessário se tratar, neste contexto, em anulação de suas cláusulas, que deverão ser consideradas abusivas, porque qualquer disposição contratual que impeça, interfira ou mitigue o elemento volitivo jurídico da vontade não pode servir a obrigar o consumidor a entregar seus dados pessoais, muito menos serve a autorizar a compra e venda destes a terceiros.

É em nome da Teoria do Diálogo das Fontes que o instituto civil dos vícios de consentimento deve ser invocado para incidir também nos contratos consumeristas e em especial naqueles que têm por base a Internet. Isso porque a citada Teoria faz com que o CDC 'converse' com o Código Civil e busque neste a supressão das eventuais omissões que aquele diploma especial possui em relação aos requisitos para formação do contrato ${ }^{58}$.

As técnicas do neuromarketing tolhem o livre arbítrio informacional necessário à manifestação da vontade que é condição inexorável de formação do contrato. No mercado de compra e venda de informações, o consentimento que autorizou

57 BRASIL. Lei $\mathbf{n}^{\circ} \mathbf{8 . 0 7 8}$, de 11 de setembro de 1990. Código de Defesa do Consumidor. 1990. Disponível em: <http://www.planalto.gov.br/ccivil_03/leis/L8078.htm>. Acesso em: 11 ago. 2016.

58 TARTUCE, Flávio. Direito Civil. Vol.3. Teoria geral dos contratos e contratos em espécie. 10. ed. Rio de Janeiro: Forense, 2015. p.50. 


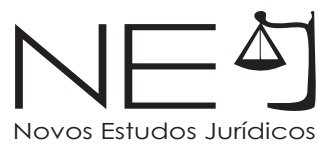

tal negociação é viciado, torto e afetado pelo impulso, pois não há a formação do ato raciocinado e internalizado de contratar, ou seja, a necessária elaboração interior acompanhada da respectiva manifestação de vontade que corresponda à internalização ponderada desta.

É importante lembrar que, para que haja a perfectibilização de qualquer negócio jurídico, é necessário o componente mais importante: a manifestação externa de vontade do consumidor ou do animus contrahendi obligationis. Para que esta ocorra, deve haver o estímulo do meio externo sobre o psiquismo que, por sua vez, levará à fase da elaboração interior. Somente depois deste processo de maturação é que poderá haver o agir jurídico (exteriorização do querer) que fundamenta o contrato.

Ocorre que o neuromarketing acaba por tornar o ser humano um autômato e escravo de seus impulsos e sentimentos, pois potencializa o cérebro reptiliano e o límbico em detrimento do córtex cerebral, já que, exacerbando as emoções e os prazeres, definha o processo de raciocínio, de elaboração interior e, consequentemente, da posterior volição da vontade.

Como todos os momentos psíquicos necessários à formação do contrato estão interligados e se sucedem um ao outro, a mencionada técnica mercadológica, por aniquilar o processo de elaboração interior, vai viciar ou comprometer a volição, o agir da vontade. Portanto, o neuromarketing infringe o cerne do contrato e seu requisito de formação, bem como os deveres contratuais da boa-fé objetiva, e os anexos de cuidado, cooperação, segurança, ética e probidade negocial. Frank Pasquale assevera que:

As mesmas revoluções tecnológicas e jurídicas que até agora têm a privacidade pessoal eviscerada podem ser usadas para protegê-la e avançar, em vez de restringir, nossas liberdades e nossa compreensão do mundo social. ${ }^{59}$

Trata-se de nefasta prática de mercado que, à luz do princípio constitucional de proteção integral do Consumidor, do CDC e dos vícios de consentimento do Código Civil, deve ser duramente combatida e repelida

59 "The same technological and legal revolutions that have so far eviscerated personal privacy can be used to protect it and to advance, rather than curtail, our freedoms and our understanding of the social world". PASQUALE, Frank. The black box society: the secret algorithms that control money and information. p. 16. 
tanto pela sociedade quanto pelo Poder Judiciário, que passa a ter notável papel no auxílio da conformação de uma sociedade mais justa, fraterna e solidária, mas, acima de tudo, sustentável e ambientalmente equilibrada também no âmbito tecnológico e digital. Somente assim os 'direitos de privacidade na internet' 60 apontados por Vinícius Borges Fortes, ora tratados no âmbito dos produtos e serviços on-line, servirão de base à regulamentação da proteção dos dados pessoais no Brasil, obtendo-se a real eficácia do direito fundamental à privacidade.

\section{CONSIDERAÇÕES FINAIS}

Como se pode observar, qualquer contrato no Brasil, para se formar e tornar-se válido, necessita de consentimento expressado pelo elemento volitivo jurídico, que é o agir ponderado em torno da aceitação à proposta feita pelo fornecedor. A vontade externada é, portanto, ato que necessita de discernimento livre e desimpedido.

Sabendo que o consentimento isento de vícios é requisito à formação do contrato, o neuromarketing influencia justamente o processo interno de decisão, afetando, consequentemente, a volição da vontade, que passa a não ser plena ou livre. Nenhuma técnica que se apoie no inconsciente ou no automatismo do cérebro humano para conformar seus interesses visando ao incremento do consumo e a lucratividade pode ser considerada uma forma sustentável de fomento à atividade econômica. O fato é que não há saúde mental possível quando o consumo está envolto em práticas que incutem no cérebro humano estímulos sensoriais, emoções e sentimentos que afetarão qualquer capacidade de livre determinismo quando o assunto é a contratação.

O neuromarketing, como vem sendo empregado atualmente, causa clara dependência do consumidor em relação aos produtos e aos serviços, porque incide diretamente nos mecanismos cerebrais responsáveis por obliterar o processo de raciocínio, logo, o salutar livre arbítrio informacional.

Ao explorar os elementos não racionais que compõem o ser humano, fragiliza este e acaba por potencializar os riscos a que a sociedade tecnológica está sujeita. 60 FORTES, Vinícius Borges. Os direitos da privacidade e a proteção de dados pessoais na internet. Rio de Janeiro: Lumen Juris, 2016. 
Com isto, diversos e nefastos efeitos socioambientais são verificados, entre eles, a síndrome da dependência tecnológica, o fomento ao consumo desenfreado e impulsivo e a perda da privacidade e da intimidade.

Portanto, o neuromarketing infringe claramente inúmeras disposições normativas brasileiras, entre elas o princípio constitucional da proteção integral do consumidor, da Dignidade da Pessoa Humana, do Meio Ambiente Ecologicamente Equilibrado, da boa-fé objetiva e dos requisitos de formação do contrato, isso sem falar do Código de Defesa do Consumidor, pois imputa ao consumidor cláusulas abusivas e prestações claramente desproporcionais e excessivas.

Pela ilicitude de tal prática, o Estado deve intervir sempre que necessário para coibi-la veementemente. É proposição do presente artigo a necessidade de uma regulamentação estatal publicitária que vede a oferta de produtos e serviços (incluindo os tecnológicos e digitais) que tenham por base o uso de qualquer técnica de neuromarketing.

É necessário lembrar que cláusulas contratuais que impeçam ou mitiguem o elemento volitivo jurídico da vontade não podem servir a obrigar o consumidor a entregar seus dados pessoais, muito menos servem a autorizar a compra e venda destes a terceiros.

Portanto, o consentimento viciado pelos estímulos sensoriais e emocionais apresentados pelo neuromarketing autoriza o consumidor a pleitear a modificação, a revisão ou a anulação das cláusulas contratuais que expropriam a informação e o submetem aos nefastos riscos decorrentes deste fenômeno. Os fornecedores, assim, devem ser dissuadidos a não utilizar das técnicas de neuromarketing para fomentar a remuneração direta ou indireta de seus produtos e serviços. Devem também ser compelidos pelo Poder Judiciário a não mais praticar a Mineração de Dados que espolia a informação. De igual modo, a compra e venda de dados pessoais dos consumidores deve ser combatida e vedada, haja vista a hipervulnerabilidade que o ambiente digital proporciona.

Somente desta forma se estará garantindo a fruição, pela sociedade, de um necessário holismo informacional que, por sua vez, irá conduzir a um processo raciocinado, ponderado e intelectualizado de consumo. Como efeito, haverá 
um progresso rumo ao almejado 'livre arbítrio' do consumidor que, uma vez consciente de seus atos, poderá livremente determinar-se em sua vida.

Por sua vez, a 'libertação consumidora' do mecanismo de amarras e dependência tecnológica será a base da Sustentabilidade preconizada na Constituição Federal de 1988, já que somente o processo de esclarecimento pela via da consciência será capaz de frear e diminuir o consumo compulsivo e artificial, bem como a obsolescência programada, o descarte de lixo eletrônico, o consumo de recursos não renováveis e a destruição da natureza.

Como tudo na teoria evolucionista de Charles Darwin, cujos organismos se adaptam ao meio para poder sobreviver, os tempos atuais e a emergência socioambiental pela qual passa o planeta Terra demandam da sociedade e dos fornecedores uma mudança de postura e atitude visando à manutenção da vida com o mínimo de dignidade e prosperidade.

Portanto, aqueles que desejarem permanecer no mercado deverão encontrar uma forma fraterna, justa e solidária de remunerar seus negócios, pois as práticas comerciais não podem mais passar pela adoção das técnicas de neuromarketing, muito menos pela Mineração de Dados e pela compra e venda de dados pessoais. O paradigma atual exige mobilidade, versatilidade e facilidade, de modo que o consumidor experencia a integração da Computação Ubíqua com a Computação Móvel diante do paradigma denominado de everyware ${ }^{61}$. É a união entre anytime, anywhere e anything, ou seja, a qualquer hora, em qualquer lugar, pode-se ter acesso a qualquer coisa, produto ou serviço por meio direto aos sites das lojas virtuais ou indireto por meio das redes sociais, estando todos estes sistemas ávidos pelos dados dos usuários.

\section{REFERÊNCIAS DAS FONTES CITADAS}

AMERICAN MARKETING ASSOCIATION. Definition of marketing. 2013. Disponível em: <https:// www.ama.org/AboutAMA/Pages/Definition-of-Marketing.aspx>. Acesso em: 11 ago. 2016.

BAUMAN, Zygmunt. Vida líquida. 2. ed. Rio de Janeiro: Zahar, 2009: Introdução.

BRASIL. Constituição da República Federativa do Brasil. Brasília, DF: Senado Federal, 1988. Disponível em: <http://www.planalto.gov.br/ccivil_03/constituicao/constituicao.htm>. Acesso em: 11 ago. 2016.

61 GREENFIELD, Adam. Everyware: the dawning age of ubiquitous computing. AIGA, New Riders, 2006. p.9. 
BRASIL. Escola Nacional de Defesa do Consumidor. A proteção de dados pessoais nas relações de consumo: para além da informação creditícia. Escola Nacional de Defesa do Consumidor; elaboração Danilo Doneda. - Brasília: SDE/DPDC, 2010. Disponível em: <http://www.justica.gov.br/seus-direitos/ consumidor/Anexos/manual-de-protecao-de-dados-pessoais.pdf>. Acesso em: 11 ago. 2016.

BRASIL. Lei n. 10.406, de 10 de janeiro de 2002. Institui o Código Civil. 2002. Disponível em: <http://www.planalto.gov.br/ccivil_03/leis/2002/L10406.htm>. Acesso em: 11 ago. 2016.

BRASIL. Lei $\mathbf{n}^{\circ}$ 8.078, de 11 de setembro de 1990. Código de Defesa do Consumidor. 1990. Disponível em: <http://www.planalto.gov.br/ccivil_03/leis/L8078.htm>. Acesso em: 11 ago. 2016.

CAMARGO, Pedro Celso Julião de. Neuromarketing: a nova pesquisa de comportamento do consumidor. São Paulo: Atlas, 2013.

CASTRO, Leandro Nunes de; FERRARI, Daniel Gomes. Introdução à mineração de dados. Conceitos básicos, algoritmos e aplicações. São Paulo: Saraiva, 2016.

CAYUELA, Oscar Malfitano; REQUENA, Ramiro Arteaga; ROMANO, Sofia Edith; SCINICA, Elsa Beatriz. Neuromarketing: para recobrar a confiança com os clientes. Trad. Maya Reyes. Rio de Janeiro: Qualitymark Editora, 2011.

COSTA, Cláudio F. Três níveis de ação. Ethica Revista Internacional de Filosofia da Moral da UFSC. Florianópolis, v.4, nº 1, jun. 2005.

DINIZ, Maria Helena. Curso de Direito Civil brasileiro. Teoria das obrigações contratuais e extracontratuais. Vol. 3. 30. ed. São Paulo: Saraiva, 2014.

DONEDA, Danilo. Da privacidade à proteção de dados pessoais. Rio de Janeiro: Renovar, 2006. DOOLEY, Roger. Brainfluence: 100 ways to persuade and convince consumers with neuromarketing. Hoboken, US: Wiley, 2011. ProQuest ebrary. Web. 24 August 2016.

FACEBOOK. Política de dados. 2015. Disponível em: <https://www.facebook.com/privacy/ explanation>. Acesso em: 13 ago. 2016.

FERREIRA Junior, Achiles Batista. Marketing digital: uma análise do Mercado 3.0. Curitiba: Intersaberes, 2015.

FRETAS, Cinthia Obladen de Almendra. A vulnerabilidade do consumidor e a exposição pública na internet. In: Aires José Rover, Fernando Galindo. (Org.). II Encontro de Internacionalização do CONPEDI/Universidad Complutense de Madrid. 1. ed.Madrid: Ediciones Laborum, 2015, v. 9. p. 76-101.

GOOGLE. Política de privacidade. 2016. Disponível em: <https://www.google.com/intl/ptBR/policies/privacy/>. Acesso em: 11 ago. 2016.

GREENFIELD, Adam. Everyware: the dawning age of ubiquitous computing. AIGA, New Riders, 2006. p.9. 
KERIN, Roger A.; HARTLEY, Steven W.; BERKOWITZ, Eric N.; RUDELIUS, W. Marketing. 8. ed. Porto Alegre: AMHG Editora Ltda, 2007.

LENT, Roberto. Neurociência da mente e do comportamento. Rio de Janeiro: Guanabara Koogan S.A, 2008.

LUIZ, Claiton. A teoria do cérebro triúnico e o neuromarketing. 2013. Disponível em: <http://linecoaching.com.br/site/a-teoria-do-cerebro-triunico-e-o-neuromarketing-parte-icerebro-reptiliano/>. Acesso em: 11 ago. 2016.

MARTINS, Fran; CORRÊA, Osmar Brina. Contratos e obrigações comerciais. 16. ed. Rio de Janeiro: Forense, 2010.

MCCLURE, Samuel M; LI, Jian; TOMLIN, Damon; CYPERT, Kim S; MONTAGUE, LAtané M; MONTAGUE, P. Read. Neural Correlates of Behavioral Preference for Culturally Familiar Drinks. Neural. Volume 44, issue 2, October 2004. p. 379-387. Disponível em: <http://www. sciencedirect.com/science/article/pii/S0896627304006129>. Acesso em: 11 ago. 2016.

MENDONÇA, Gilson Martins; KOZICKI, Katya; COELHO, Sérgio Reis. O princípio da vulnerabilidade e as técnicas de neuromarketing: aprofundando o consumo como vontade irrefletida. Revista Scientia Iuris. Londrina, v. 18, nº 1. 2014.

PAMPLONA, Fabrício; PERUZZO, Marcelo. Um milhão de motivos para se aprender neuromarketing. 2010. Disponível em: <http://www.marceloperuzzo.com.br/index.php/ conteudo/artigos/68-um-milhao-de-motivos-para-se-aprender-neuromarketing $>$. Acesso em: 11 ago. 2016.

PASQUALE, Frank. The black box society: the secret algorithms that control money and information. Cambridge: Harvard University Press, 2015.

PURVES, Dale; AUGUSTINE, George J; FITZPATRICK, David; HALL, William C; LAMANTIA, Anthony-Samuel. Neurociências. 4. ed. São Paulo: Artmed Editora, 2010.

RODOTÀ, Stefano. A vida na sociedade da vigilância: a privacidade hoje. Tradução de Danilo Doneda e Luciana Cabral Doneda. Organização, seleção e apresentação de Maria Celina Bodin de Moraes. Rio de Janeiro: Renovar, 2008.

SCHENKMAN, Margaret L; BOWMAN, James P; GISBERT, Robyn L; BUTLER, Russel B. Neurociência clínica e reabilitação. Barueri: Manole, 2016.

TAMBARA, Isabelle; BATISTA, Osvaldo Henrique dos Santos; FREITAS, Cinthia Obladen de Almendra. A Proteção do Consumidor e as Técnicas de Neuromarketing no Comércio Eletrônico que Potencializam sua Vulnerabilidade. Revista Direito Empresarial (Curitiba). Belo Horizonte, v. 11, 2014. p. 89-107.

TARTUCE, Flávio. Direito Civil. Vol.3. Teoria geral dos contratos e contratos em espécie. 10. ed. Rio de Janeiro: Forense, 2015.

Recebido em: janeiro/2017

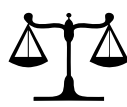

Aprovado em: outubro/2017 